\title{
THE INFLUENCE OF ROAD CORRIDORS ON THE SOCIAL CONDITION OF ADJACENT AREAS
}

\author{
Rafał Wiśniewski, Tomasz Komornicki \\ Institute of Geography and Spatial Organization \\ Polish Academy of Sciencess \\ Twarda St. 51/55, 00-818 Warsaw, Poland \\ rafwis@twarda.pan.pl,t.komorn@twarda.pan.pl
}

\begin{abstract}
Accessibility of public services constitutes an essential element, defining the level of development of a given region and the standard of living of its inhabitants. The present report attempts to shed light on the spatial accessibility to services in the local dimension, with consideration of the important factor, constituted by the development of road infrastructure, which, side by side with economic advantages (enhancement of competitiveness and attractiveness) and improvement of accessibility, should also bring social effects, in particular - increase of spatial mobility and improvement of the overall living standards and the quality of life (Domańska, 2006). The significance of the development of road infrastructure and its influence on the changes in potential accessibility have also been analysed.
\end{abstract}

Keywords: transport-related investments, motorways, accessibility, public services.

\section{Introduction}

The accessibility of the public services constitutes a broad research field, investigated under numerous aspects, such as supply of services (both infrastructural and social) and their financing (Rattsø 2002; Ackerman \& Heinzerling 2004; de Bettignies \& Ross 2004), effectiveness of the services rendered (King \& Pitchford 2000), or the organisational matters (Daniels \& Trebilcock 1996; Besley \& Ghatak 2001; Svallfors \& Taylor-Gooby 2005). An essential element of these analyses is the accessibility in the spatial context. The studies, concerning the spatial accessibility of this kind of service are most often conducted on the macroscale, at the level of individual countries or regions (OECD 2002; Vogel 2003; Moene \& Wallersein 2006; Breuer et al. 2013; ESPON TRACC ${ }^{1}$ and ESPON SeGI ${ }^{2}$ studies), but quite rarely they are concerned with the local level.

1 Broad analyses of transport-wise accessibility in the regional perspective, with consideration of access to services and labour markets, are contained in the volume by Stępniak M., Spiekermann K. (eds.), 2013. Transport accessibility at regional scale in Europe. EUROPA XXI, Volume 24, Warsaw: IGSO PAS.

2 Analyses of accessibility regarding public services are presented in Komornicki T. (ed.), 2013. Services of General Interest in European Union. EUROPA XXI, Volume 23, Warsaw: IGSO PAS. 
Access to public services is an important element, determining the level of development of a given region, as well as the living standards of its inhabitants. Accessibility can be analysed as a spatial variable, corresponding to the facility of reaching a destination, expressed through physical distance, time, or cost (Guzik 2003), and as a social or economic variable, corresponding to the ability of a person to take advantage of a given service. Accessibility depends, therefore, in particular, upon the socio-demographic factors, the wealth of the society, etc.

An attempt is undertaken in the study here reported of presenting the spatial accessibility to the services in the local dimension, with consideration of the essential factor of development of the road infrastructure, which, side by side with economic advantages (enhancement of competitiveness and attractiveness) and improvement of accessibility, ought also bring social effects, including increased spatial mobility and improvement of the general standards and quality of life (Domańska 2006). The significance of development the road infrastructure and its influence on changes in accessibility have also been analysed.

Social situation at the local level was analysed mainly through the changes in accessibility to selected public services, that is - administrative and social services (public administration of the provincial and county levels, health care centres, hospitals, high schools, universities and other tertiary education establishments, bank outlets, shopping centres, railway stations, etc.), with omission of the municipal services (like waste management, energy supply, etc.), and the accessibility of the local labour markets. The analysis was carried out on the basis of the questionnaire-based surveys. This analysis refers, therefore, to the social perception of the variables considered. The information from this analysis was complemented by the interviews, conducted with the representatives of the local (municipal) authorities. Direct interrelations were analysed, as well, between the quality of life and the level of safety, on the one hand, and the influence of the road corridors, on the other hand (based on the survey study).

\section{Data sources and methodological observations}

In the study of spatial accessibility the broadly used indicator of potential accessibility was applied ${ }^{3}$. The study was carried out for the closed set of all the municipalities in Poland. Analysis was repeated with application of various functions of spatial resistance, typical for the short and long travels. The database of the road network and the computer application OGAM, elaborated at the Institute of Geography and Spatial Organization, Polish Academy of Sciences, were made use of for the purposes of the study. In the study of accessibility the final effect was simulated, to be achieved after the termination of all the currently realised large road projects (the ones, on which construction works have been already started). The magnitude of the effect was related to the national averages.

The primary source of information on the social perception of changes in spatial accessibility to services was constituted by the output from the field research, carried out in the framework of the project Multicriteria assessment of the influence of selected road corridors on the natural environment and on the socio-economic development of the adjacent areas ${ }^{4}$. This research was composed of two parts: in-depth interviews with the representatives of the local authorities, and the

3 For methodological details, compare T. Komornicki, P .Śleszyński, P. Rosik, W. Pomianowski (2010) as well as the website http://www.igipz.pan.pl/accessibility/pl/.

4 This project was financed with the means from the National Science Center, project no. NN 306564940. 
questionnaire-based surveys, carried out in these municipalities, through which the road corridors, selected for the analysis, pass.

The interviews were carried out in 17 municipalities (Table 1), in which also questionnaire-based surveys were performed, by the intermediary of the primary schools ( 33 schools). The questionnaires were transmitted to the parents or caretakers of the pupils from the respective schools. The respondents were asked to fill in the questionnaires, and to hand them back, by the intermediary of their children, to the teachers, who were involved in the study. The sample was estimated on the basis of the criterion of participation of the parents and caretakers of children in school age. This method was applied for two reasons. First, use of schools as intermediaries in reaching the respondents allowed for achieving relatively high rates of response, higher than, for instance, in the case of sending by regular mail, and that with quite low costs. Second, the results obtained from the thus selected sample reflect the opinions of the most active part of the community analysed: these are the persons, who are relatively mobile (hence making use of the road infrastructure, considered in the study), economically active, having stable life situation, and working for the upkeep of the family.

Altogether 6460 questionnaires were sent out. The overall rate of response was $41 \%$. The questionnaires concerned the functioning and the use of the particular segments of the road corridors.

Table 1. The investigated road corridors and municipalities

\begin{tabular}{|l|l|}
\hline \multicolumn{1}{|c|}{ Road corridor } & \multicolumn{1}{c|}{ Municipalities considered } \\
\hline A1 Pruszcz Gdański-Grudziądz and DK 91 & Pelplin, Smętowo Graniczne, Warlubie \\
\hline DK 8 S Kudowa-Zdrój-Wrocław & Niemcza, Bardo, Szczytna \\
\hline S8 Radzymin-Wyszków & Dąbrówka, Zabrodzie, Wyszków \\
\hline A4 Wrocław-Opole and DK 94 & Domaniów, Dąbrowa, Lewin Brzeski \\
\hline DK 17 Garwolin-Kurów & Sobolew, Trojanów, Kurów \\
\hline DK 8 N Augustów-Budzisko & Nowinka, Szypliszki \\
\hline
\end{tabular}

Source: own elaboration.

The results were also used of the analyses, performed for the purposes of the evaluation study, entitled "The influence of construction of motorways and expressways on the socio-economic and territorial development of Poland", carried out in 2013 upon the commission from the Ministry of Regional Development"5. The selection of the units for the case studies was somewhat different in the evaluation study, carried out for the Ministry of Regional Development. This selection was done on the basis of the criteria, analogous to those applied for the research project here referred to, and, in addition, with consideration of the nature of support, obtained from the funds of the European Union for the particular road projects, and of the date of termination of a given undertaking. Besides, this study, in view of its applied character, concerned only the new roads and did not account for any segments repaired. Ultimately, in the evaluation study, the municipalities were considered, situated in the neighbourhood of eight new routes, including three motorways (A1 - one segment, A2 and A4 - two segments each), and three expressways (S3, S7, and S8). The questions, asked of the respondents, were also different. An important part of the questionnaire was devoted to the very process of construction of new roads, involvement of the local construction companies, etc. From

5 This study encompassed 12 municipalities, namely those of Mszana, Parzęczew, Dąbie, Mińsk Mazowiecki (urban and rural municipality), Nowogrodziec, Brzesko, Myślibórz, Pyrzyce, Pasłęk, Choroszcz, and Tykocin. 
the point of view of the objectives of the present report it was assumed that of importance were the questions, concerning the broadly understood corridor effect and the difficulties in communication between the two sides of the new transport routes. Realisation of this questionnaire-based inquiry was supported by the commissioning organisation (Ministry of Regional Development), which allowed for the achievement of a very high response rate (more than 63\%). Finally, 5406 questionnaires were obtained, fulfilling the formal requirements.

\section{The influence of the road construction projects on the road-based accessibility}

The advantageous influence of the currently implemented road projects (Fig. 1 - effects only for the investment projects supported with the means from the European Union), expressed through the improvement in the potential road accessibility, encompasses a large part of the country, including an important proportion of the rural areas of interest here for us. The reach of the influence is in an obvious manner dependent upon the applied function of space resistance. Assumption of a relatively "smaller" resistance (in the nominal terms - corresponding to the longer travels) means that the investments made into roads brought advantages, of various magnitude, for the majority of the rural areas in Poland. Assumption of a higher resistance (short travels, Fig. 2) makes it possible to grasp the situation in the immediate neighbourhood of the projects considered. The assessment of the changes, having taken place, is made in the context of the current levels of the potential accessibility.

The biggest beneficiaries of the investments, made in the time period here accounted for, are the regions of Lodz (motorways A1 and A2), Cuiavia-Pomerania (A1), Pomerania (A1 and the northern segments of S7), as well as the provinces of Subcarpathia and Małopolska (the belt, stretching from Tarnów to Przemyśl, A4). Besides, positive effects are visible in the area of Szczecin (northern segments of S3), and in Masovia (A2). The indirect advantages, accruing from the new investment projects, arise also within some areas located outside of their immediate neighbourhood. An instance can be provided by the southern part of Lublin province (owing to A4), the area of Słupsk (owing to A1), and Podlasie (owing to A2). Interpretation of these observations, though, is not unambiguous. We may, namely, indirectly infer weak accessibility over the routes, linking the regions mentioned straight with the rest of the country (the shortest, time-wise, turn out to be the paths around, taking advantage of the freshly appearing opportunities, associated with the new infrastructure). The analysis of improvement of accessibility confirms, in addition, a clearly higher effectiveness of construction of the motorways than of the expressways. It is also important, from the point of view of rural areas, that owing to the improvement of accessibility to some of the big cities, different gravity orientations appear than it would result from the administrative division.

At the same time, it should be remembered that the character of the motorway (and, to a lesser degree, also of the expressway) causes lack of influence of its construction on improvement of accessibility on the local scale. Moreover, the so-called corridor effect might be observed on such a scale. The awareness as to the associated threat is well evidenced by the postulates of the local communities, aiming at the construction of new nodes along the planned routes. 


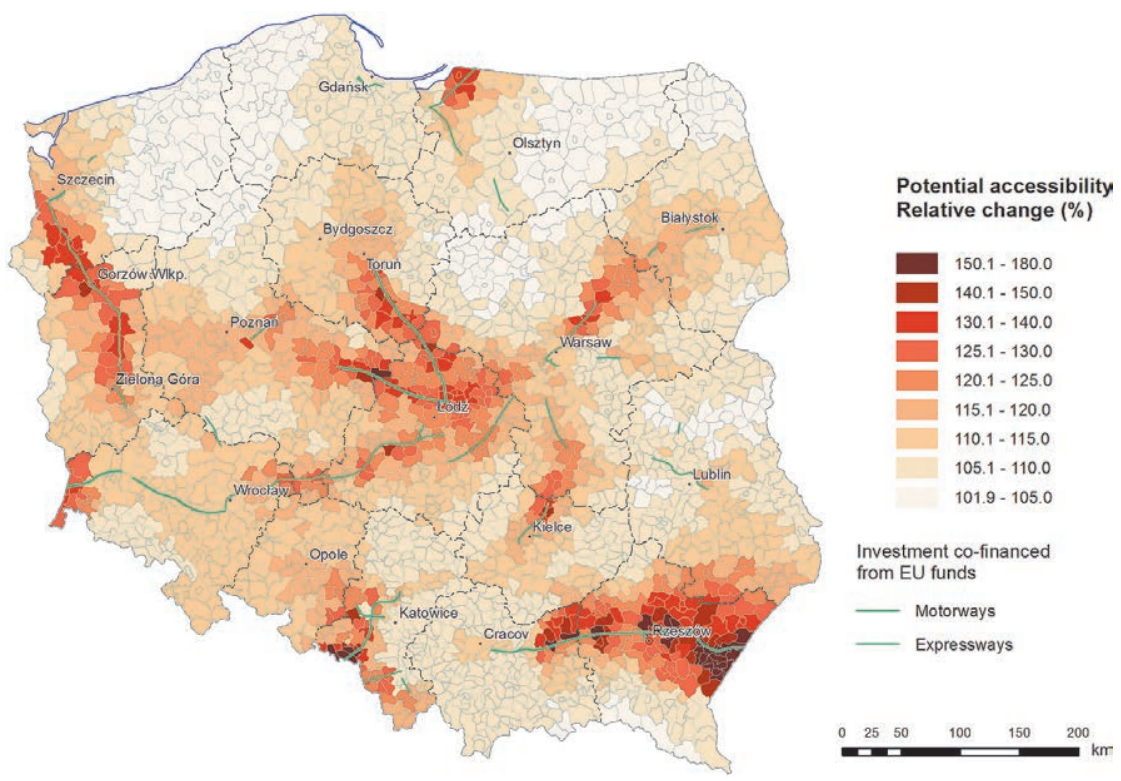

Figure 1. Relative change in the domestic potential accessibility of municipalities in Poland in the years 2004-2013 due to realisation of the road projects with support from the EU means

Source: Komornicki et al. 2013, p. 64.

\section{Assessment of accessibility to public service}

Accessibility to selected public service has been analysed as to a couple of aspects, namely those of:

- particular categories of service in the perspective of all the case studies jointly;

- accessibility in the context of the degree of motorisation of the households;

- accessibility according to the economic status and age of the respondent.

In the opinion of the respondents, the highest accessibility was enjoyed - irrespective of the road category considered - by the shopping centres (Fig. 2). This may be the effect of their high number and their mutual positioning in space. 


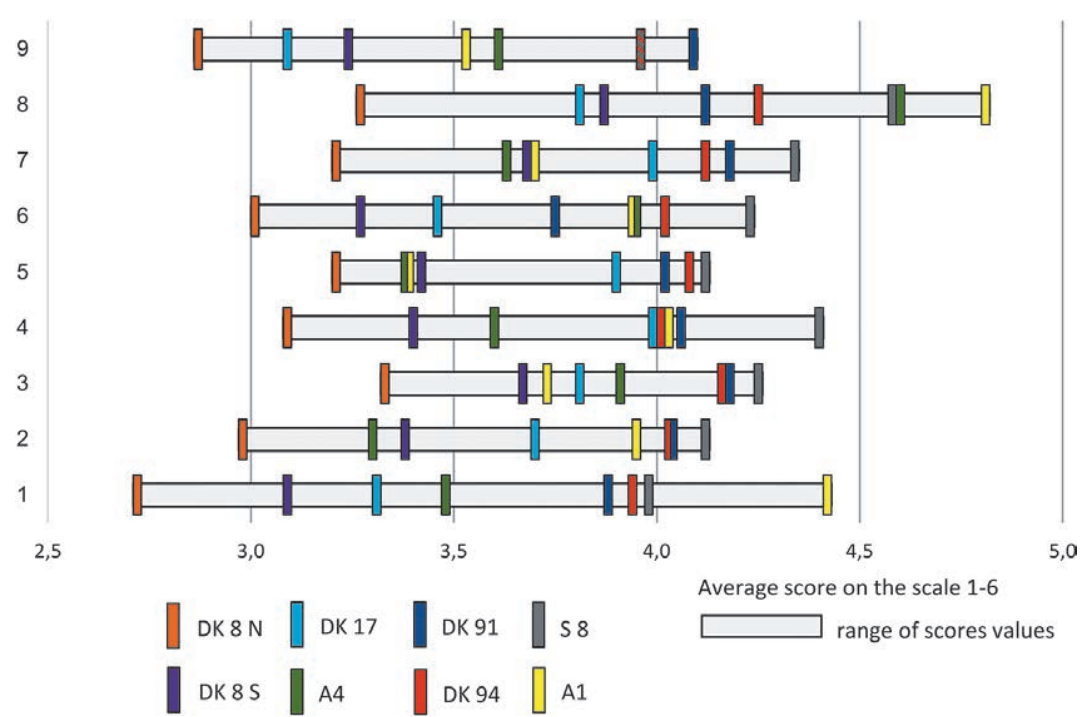

1 - provincial administration, 2 - county administration, 3 - health care centres, 4 - hospitals, 5 - high schools, 6 - universities and other tertiary schools, 7 - banks, 8 - shopping centres, 9 - railway stations

Figure 2. Average assessments of accessibility to selected services ${ }^{6}$ Source: own elaboration on the basis of the questionnaire survey.

Not without significance are also the studies, carried out by the investors, regarding the locations of the shopping facilities and the related potential demand for the services offered. There exist important differences as to the assessment of accessibility within this category. There is a clear supremacy of the assessment of accessibility to the shopping centres via the motorways as compared to the assessment of accessibility for the very same motivation with respect to the national roads (the cases of A1 and DK91, and of A4 and DK94). An especially high assessment of accessibility to the shopping centres with the motorways may also result from the comparison of accessibility to these shopping centres with the national roads. The lowest assessments of accessibility to the shopping centres concern the national road DK8 on its segment between Augustów and Budzisko (3.27 on the 6 -point scale). This is the consequence of the low density of shopping centres in the north-eastern Poland, which entails a long and difficult (in view of traffic density, especially of trucks) travel to the shopping centres, located in Suwałki and Augustów.

The accessibility of the health care centres was assessed rather positively (presumably in view of the existence of such centres in each seat of municipality), similarly as that of banks (average scores from 3.21 in the case of DK 8 between Augustów and Budzisko to 4.34 in the case of the expressway S8). Given, though the dense network of bank outlets in Poland one could expect a higher average score.

The respondents assessed in a similar manner the accessibility to the educational services (universities, other higher schools, secondary schools) and to the hospitals. The lowest scores were

6 In this figure, and in the remaining ones, the notation of DK8 $\mathrm{N}$ refers to the northern segment of the national road no. 8, Augustów-Budzisko, in distinction from the analysed southern segment of the same road, denoted in the figures DK8 $\mathrm{S}$ (Kudowa-Zdrój-Wrocław). 
assigned the accessibility to the railway stations (treated as the starting points for longer travels) and to the provincial as well as county administration.

The biggest differences in the assessment of accessibility to services within the particular case studies were observed for the motorways A1 and A4, for which the character of the road influences to a high extent the accessibility to selected public services, especially those of a higher rank, located primarily in the provincial capitals (universities, other tertiary schools, large shopping centres, provincial administration). This observation is confirmed by the low assessment of accessibility with motorways to the county centres and secondary schools. The courses of the motorway routes, toll payment, lack of possibility of entering them in an arbitrary place, all this causes that in the case of short distance travel motivations (county level administration, secondary schools) the respondents choose to drive over other roads, which guarantee a relatively faster trip than over the motorway, and that without additional costs. Besides, everyday commuting to secondary schools takes usually place with public transport means, which use national and local roads, and not the motorways. The factors mentioned could exert influence in the direction of low scores assigned the accessibility to both county administration and secondary schools, the latter also being usually located in county seats.

Thus, the development of motorways and expressways has not had an impact on the level of accessibility to the local services, but increased the accessibility to the provincial centres. In connection with the improvement of accessibility with private transport means to the provincial capitals, the accessibility to services there located (mainly the higher order services, that is - higher education establishments, specialised health care facilities, and cultural services) improved as well, which was confirmed by both the responses to questionnaires and the interviews, carried out in the municipal centres.

In the comparison performed, the decidedly worst assessments are observed for these road corridors, for which no important infrastructural investment projects have been realised (except for modernisation), especially if this was coupled with high traffic intensity on the segments considered (in particular: DK8 over the segment Augustów-Budzisko). The best accessibility to the here analysed public services - no surprise - is secured by the fast traffic roads, and that despite the frequent necessity of taking a relatively long way to the nearest motorway junction or the entry to expressway. Besides, high scores for the accessibility to the services considered were also assigned in the cases of two national roads, parallel to the motorways A1 and A4. This may be the effect of a shift of the transit traffic (or at least a part of it) over to the motorways, leading to the decreased traffic intensity on the national roads. This positive effect could result in the relatively high scores for these national roads. The interviews suggest that the local communities take advantage of the motorway infrastructure to a moderate degree, and the majority of their movements, linked with the use of the services considered, take place over the national and provincial roads.

Of importance in the analyses of accessibility is the definite means of transport, used in movements. These households, which dispose of at least one car, irrespective of the number of persons in the household, have bigger possibilities of movement than the members of the households, who use exclusively public transport. The mobility of the former is higher, both the obligatory one (e.g. job and school commuting), and the optional one (e.g. weekend trips, doing shopping in the shopping centres), see Taylor (1999).

The questionnaire-based survey demonstrated that the average assessment of accessibility to the public services, in total, by the persons not having cars does not differ significantly from that by the car owners, and is in some cases higher, even with respect to the fast traffic roads. This result may be the consequence of both the objective organisational and infrastructural factors (e.g. an extensive 
network of connections covered by public transport, with sufficiently high frequency of connections), and the subjective factors, related to the completely different expectations of the car owners and the persons not owning a car.

The biggest differences in scores between the car owners and the remaining persons were observed in the case of inhabitants of the municipalities, situated along the segment of the national road DK8 between Augustów and Budzisko (Fig. 3 f). This may be the effect of the relatively intensive traffic and its character (an important part of the road traffic is constituted by the transit of trucks). It can be supposed that the persons not owning a car perceive to a much lesser degree the inconvenience, associated with this kind of traffic, than the car owners, and hence the generally higher assessment of accessibility to the considered services by the persons using public transport.

a) $\mathbf{A 1}$

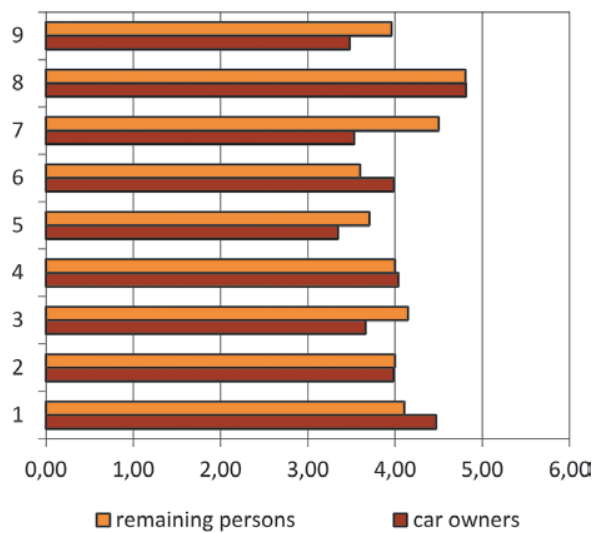

c) $\mathrm{A4}$

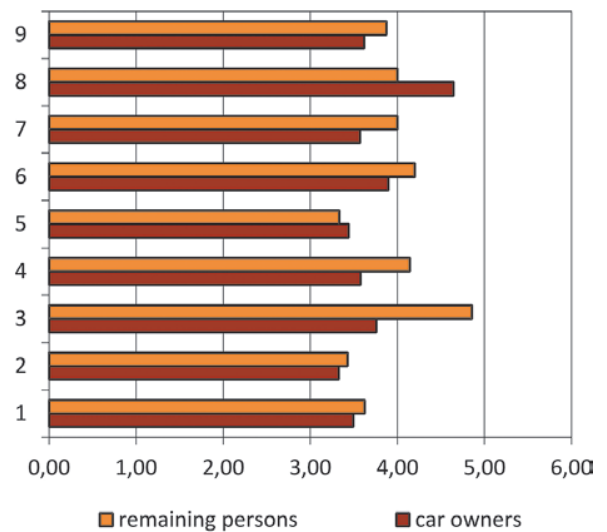

b) DK91

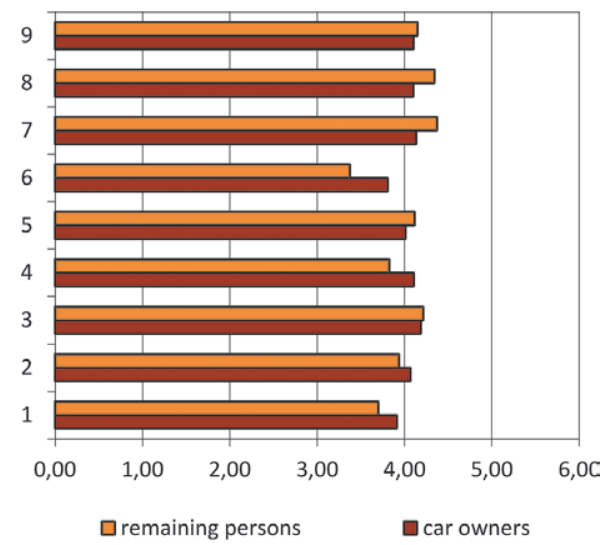

d) DK94

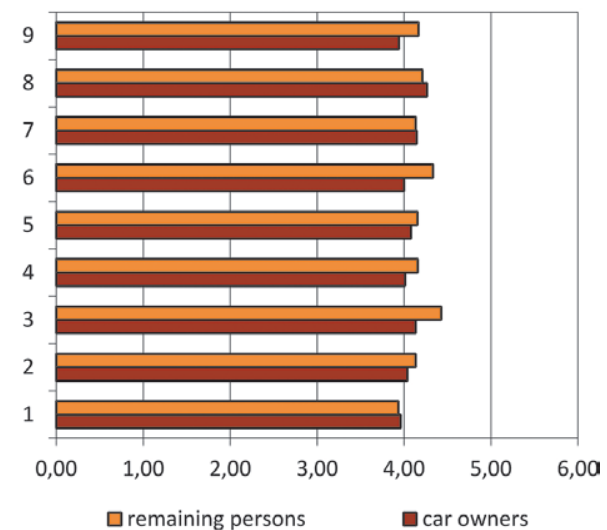


e) $\mathrm{S} 8$

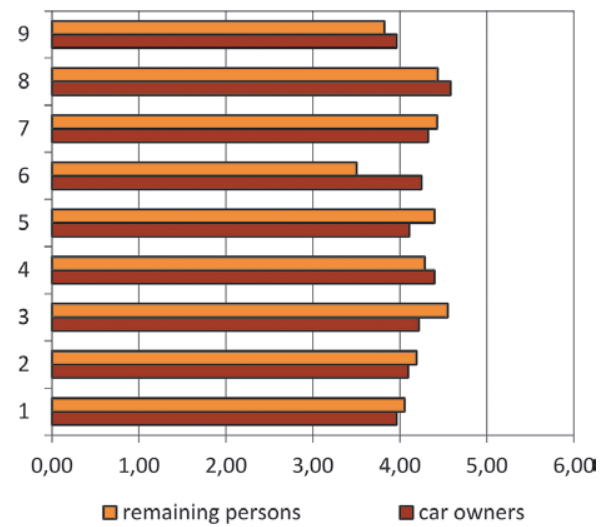

g) DK8 S

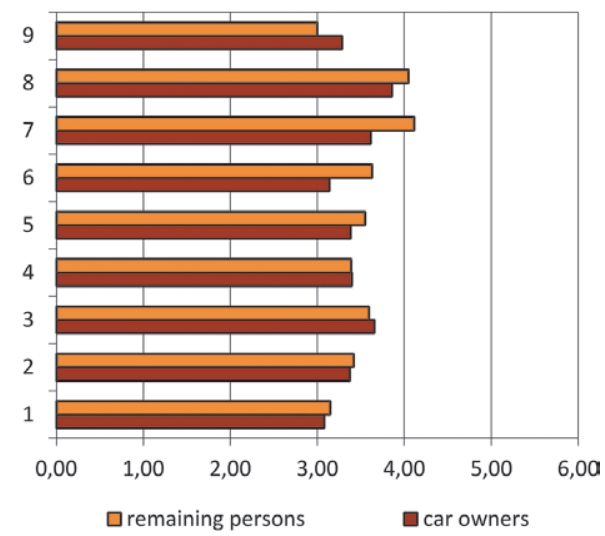

f) DK8 $\mathrm{N}$

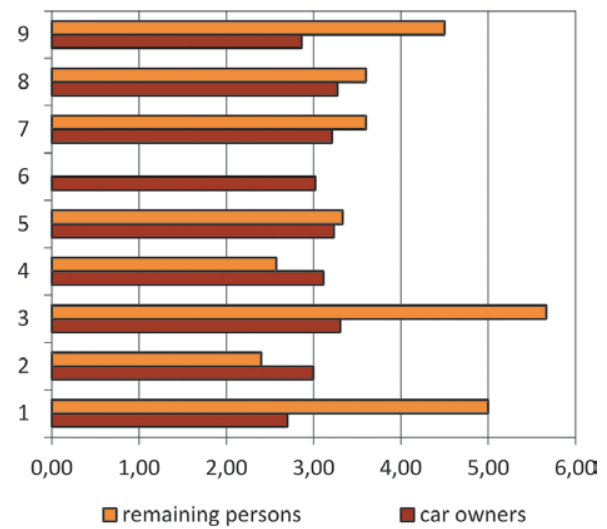

h) DK17

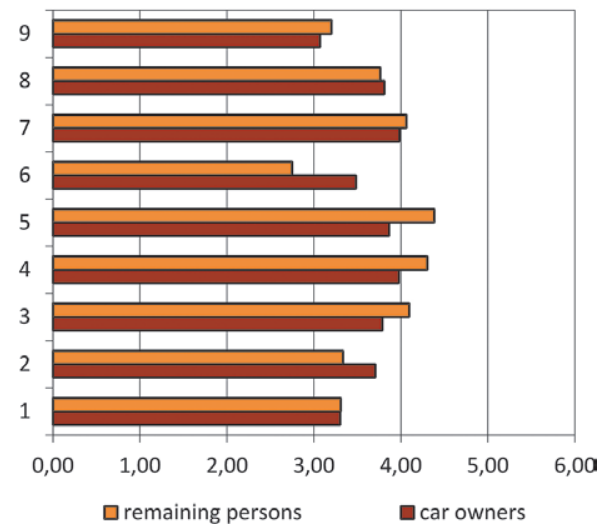

1 - provincial administration, 2 - county administration, 3 - health care centres, 4 - hospitals, 5 - high schools, 6 - universities and other tertiary schools, 7 - banks, 8 - shopping centres, 9 - railway stations

Figure 3. Average assessment of accessibility to selected public services by the car owners and the remaining persons

Source: own elaboration on the basis of the questionnaire survey.

It is not surprising, on the other hand, that the persons not owning a car assess better, in general terms, the accessibility to the selected services via the national roads than using the motorways (A1/DK91 and A4/DK94). Construction and opening of new motorways has not contributed to the appearance of new coach lines, while the existing public transport connections are realised over the other roads (national, provincial, county roads). Then, the similarly high assessment of the accessibility over the national roads, parallel to the motorways, expressed by the car owners, results from the partial transfer of the transit traffic from the national roads to the motorways, so that time of travel and convenience could have improved significantly. A reflection of this is seen in the relatively high assessments of accessibility to public service via the national roads 91 and 94 (Figs. 3 b, d).

Concerning the economic status, analysis focused on two groups of persons, i.e. those employed and conducting own business (Fig. 4), that is - the social groups, which are most mobile and make most often use of the road infrastructure. 
The assessments, expressed by these two groups, differed depending upon the road corridor and the nature of service. The persons employed and conducting an own business assess as the highest the accessibility to the shopping centres (supposedly with an own car), that is - the travel motivation, which is quite facultative and realised with relatively low frequency. In the case of the employed and the entrepreneurs low scores, given the accessibility to county and provincial centres, may result from the high frequencies of movements, causing that they are felt as burdensome (everyday job commuting, doing business trips, and going through formalities, associated with the conduct of business, etc.).

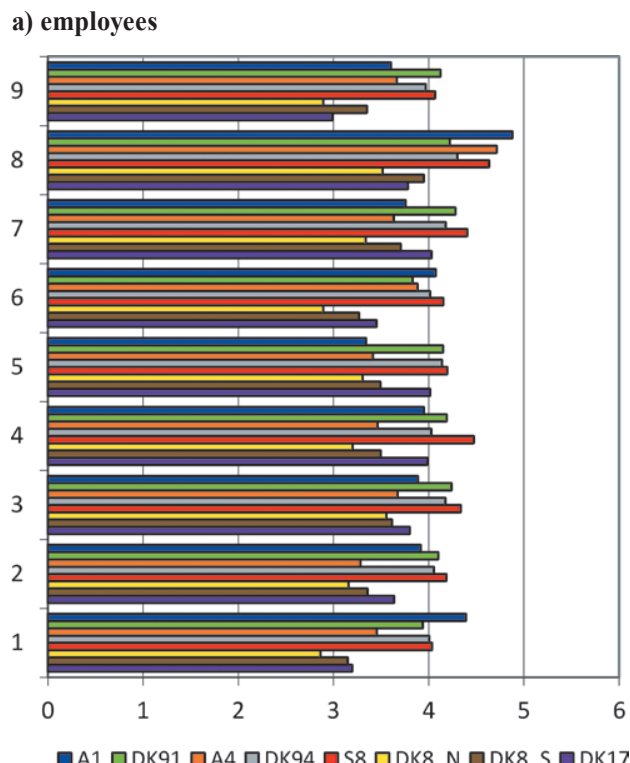

\section{b) entrepreneurs}

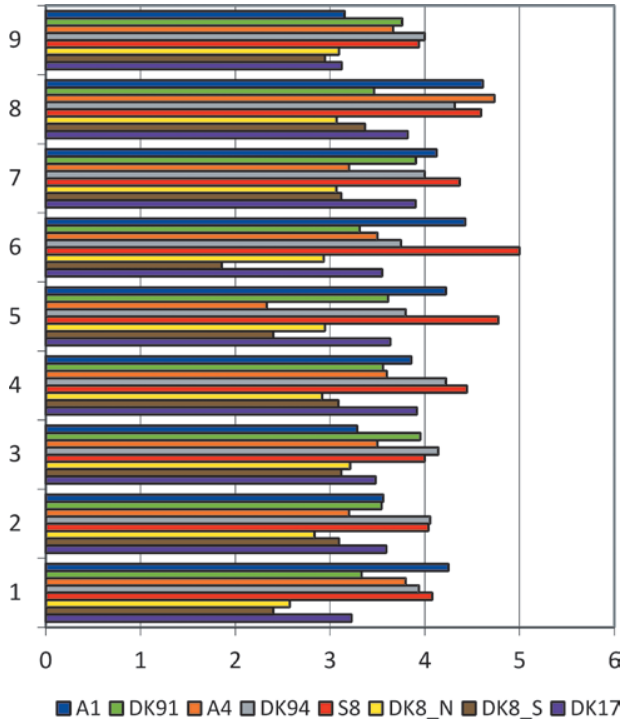

1 - provincial administration, 2 - county administration, 3 - health care centres, 4 - hospitals, 5 - high schools, 6 - universities and other tertiary schools, 7 - banks, 8 - shopping centres, 9 - railway stations

Figure 4. Average assessment of accessibility to selected public services according to economic status Source: own elaboration on the basis of the questionnaire survey.

Social perception of accessibility to the particular kinds of services differs significantly, depending upon the age of respondents. In general terms, the highest scores of accessibility to the analysed services were given by the persons aged $45-54$ years, while the lowest - by the persons aged 35-44 years.

\section{Travel motivations and frequency of using the road corridors}

Travel motivations are closely linked with the frequencies of travels. Depending upon the motivation, they are also realised over various categories of roads. This is mainly associated with the character of travel and the related cost. The most interesting are the comparisons, carried out for these road corridors, where a motorway and a parallel national road are located. 
The following travel motivations were accounted for in the questionnaire-based study: work, school, university, bringing children to school or to kindergarten, shopping, leisure and recreation, social or family reasons, business and administrative matters, and health care (separately: hospital and dispensary). Special attention was paid to the decision of the respondents in the case of two road corridors, namely A1/DK91, and A4/DK94. Four motivations were analysed, characterised by the highest numbers of responses, that is: job commuting, shopping, recreation and culture, as well as social and family reasons.

In the daily job commuting the national roads are taken first of all. This is the effect, in particular, of the economic calculation (toll payment on the motorway), time of travel, as well as mutual location of labour markets and motorway junctions. A bit more than $16 \%$ of the daily job commuting of the respondents from the municipalities of Pelplin, Smętowo Graniczne and Warlubie takes place over the motorway. In the remaining cases the national road is chosen, and that irrespective of the distance covered, which implies that even for longer travels in job commuting (e.g. to Gdansk), the economic aspect is considered more important than time (Fig. 5a). The situation is similar for the road corridor A4/DK94, where $13.4 \%$ of the respondents from the municipalities of Domaniów, Dąbrowa, and Lewin Brzeski use the motorway in their daily job commuting. The remaining part of the respondents choose the alternative, free of charge, national road (Fig. 5b).

a)

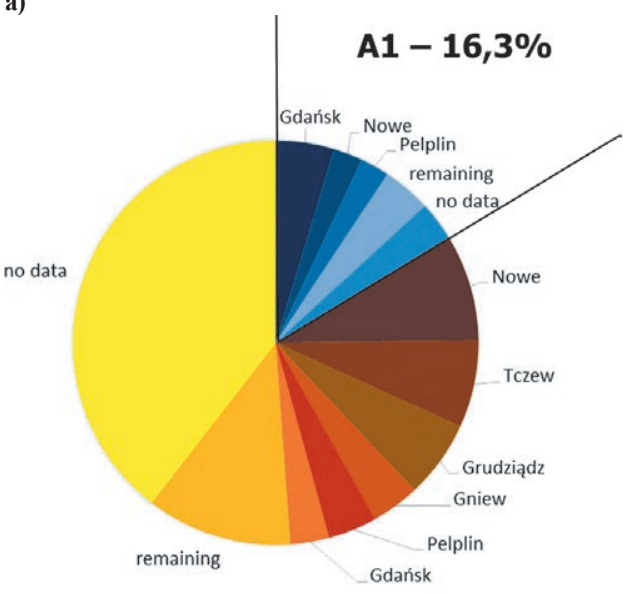

b)

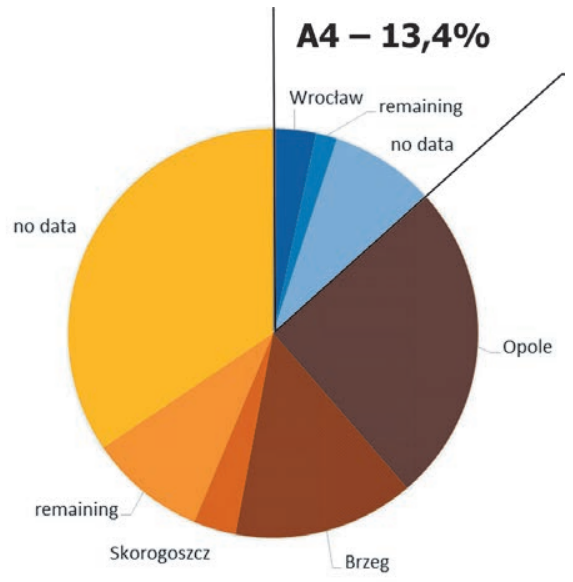

DK91 - 83,7\%

DK94 - 86,6\%

Figure 5. The structure of job commuting travels according to the road categories and directions (road corridors A1/DK91 and A4/DK94)

Source: own elaboration on the basis of the questionnaire survey.

The remaining three travel motivations (shopping, recreation and culture, and socialising and family matters) are being realised decidedly less frequently (the most often given response was "once in a month or less"). In this context, a clear majority of respondents declared that they travel over the motorway when going on such travels. In the situation of sporadic use of the motorway the toll fees are no longer the barrier, and the main factors are time and convenience of travelling.

For the inhabitants of the analysed municipalities in the road corridor A1/DK91 the basic direction of travels in the framework of the motivations analysed is Gdansk, even in the case of the respondents 
from the municipality of Warlubie, situated in the northern part of the Cuiavian-Pomeranian province. As regards the road corridor A4/DK94, the dominating place of realisation of the analysed travel objectives is Wrocław. Attention is also attracted to the sporadic responses, specifying shopping trips to Berlin.

The remaining movements, such as school commuting or bringing children to school or to kindergarten (i.e., movements of the local reach) are realised over the national roads or the other kinds of roads. The situation is similar with respect to commuting to universities. The cases of using cars in this category are quite rare among the responses. The frequencies of movements having the remaining kinds of objectives (health care - dispensaries and hospitals, business and administrative matters) are conditioned by the nature of these motivations. They are realised infrequently, not more often than once a month. The majority of the respondents use in all these situations the cost-free national roads.

The questionnaire-based survey brought interesting results as to the changes in frequency of the use of the services analysed. Thus, increase of movements was noted along all the road corridors considered in the study. Yet, the highest increase was observed for the travels to the shopping centres (Fig. 6). It is to be noted that there has been a relatively significant increase in the frequency of movements realised optionally (shopping centres, holiday and weekend outings, cinema and the like).

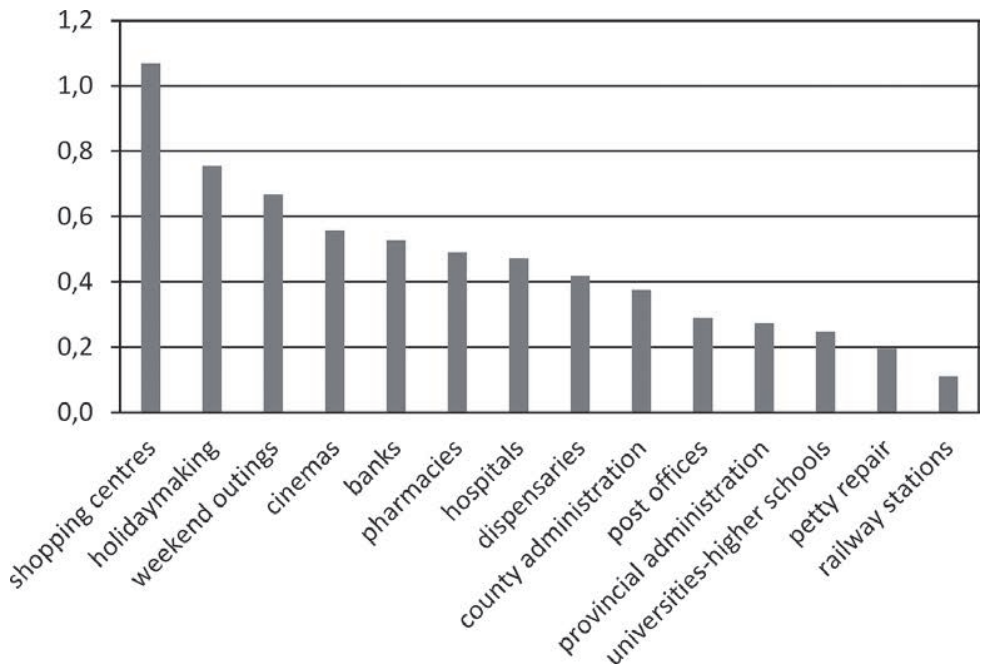

(scale of assessments: from -3 to +3 , where -3 denotes decreased frequency, while +3 corresponds to increased frequency of use of the service).

Figure 6. Changes in the frequency of taking advantage of definite services Source: own elaboration on the basis of the questionnaire survey.

The evaluation of the changes in the use of the road corridors, which might have resulted from the appearance of the new road infrastructure, was possible in the case of analysis of results from the study for the motorway A1 and national road DK91, motorway A4 and national road DK94, as well as the expressway S8. The purpose of the respective question was to inquire to what extent the appearance of the alternative possibility of travelling or the change in the road category (the case of S8) influenced the changes in frequency of using the various kinds of service (provincial and county administration, health care - dispensaries, hospitals and pharmacies, banks, post offices, large shopping centres, weekend and holiday trips, institutions of culture, etc.). 
For the three road corridors mentioned there were no radical changes in the use of the analysed services (Fig. 7). The changes observed took a similar course as for the other analysed national roads, so that it can be supposed that it was not the alternative fast traffic road that became the impulse for the increase of mobility. Yet, in the case of the motorways and expressways the trips to the shopping centres take place over bigger physical distances. Appearance of the fast traffic routes, and hence shortening of the travel times, influenced in a positive manner the levels of the population mobility. The apparent small change in the frequency of use of the motorway A4 and the national road no. 94 may be the consequence of stabilisation of definite behaviour patterns, resulting from the longer period of functioning of the fast traffic road than this is the case for the motorway A1.

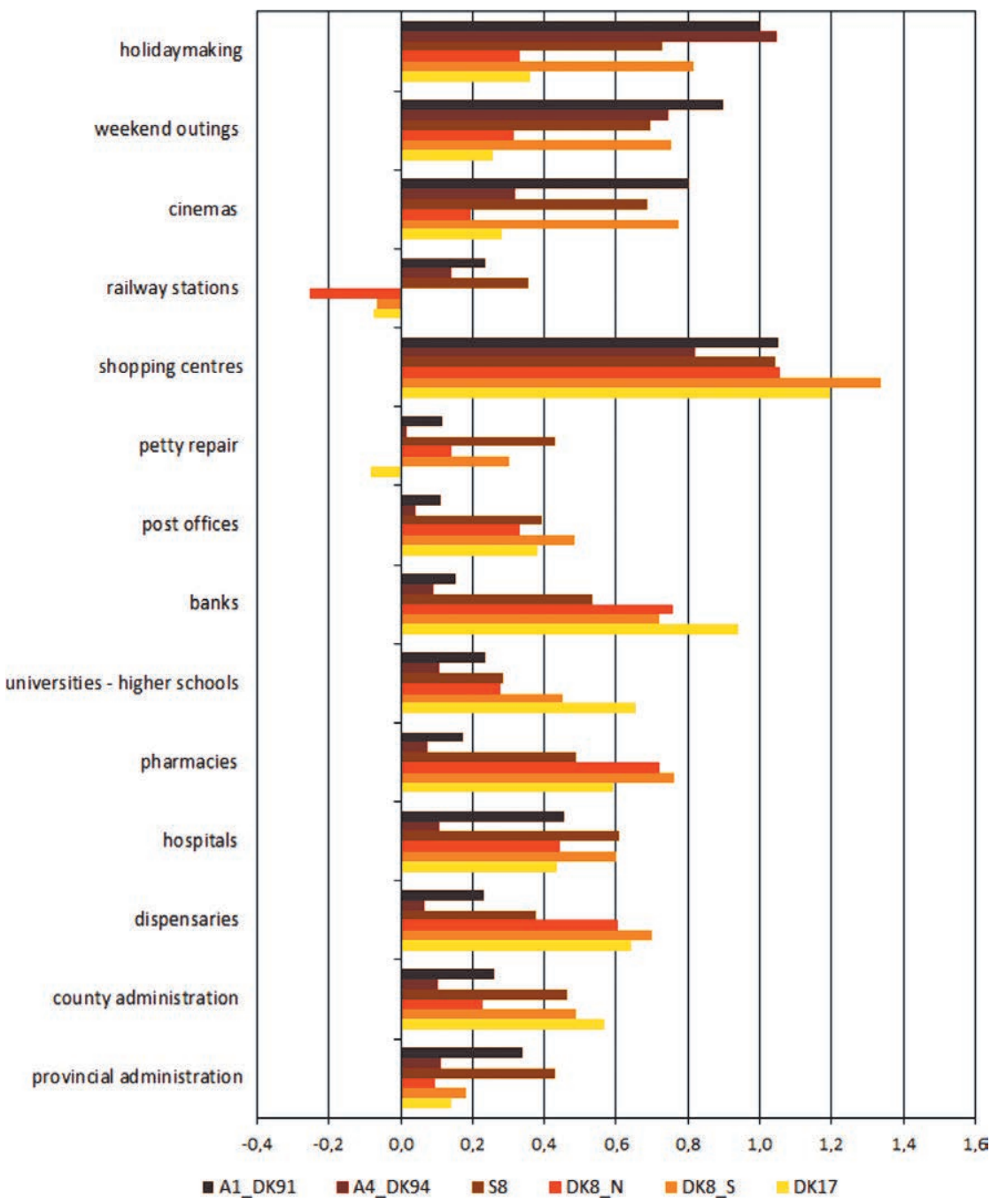

(scale of assessments: from -3 to +3 , where -3 denotes decreased frequency, while +3 corresponds to increased frequency of use of the service).

Figure 7. Changes in the frequency of taking advantage of definite services according to the road corridors Source: own elaboration on the basis of the questionnaire survey. 
While one could observe an increased frequency of use of the services considered, changes did not occur as to the places, in which these services were used, even in the cases of these corridors, where fast traffic roads started to function. This fact is associated, first of all, with the local character of the services investigated. The most pronounced changes concerned the trips to the shopping centres. The question, though, remains, whether it was the appearance of the fast traffic road (A1 and A4) that entailed the change in the location, at which use was made of the shopping centre, or perhaps it was the location of the shopping centre that forced the change? It can be concluded from the investigations carried out that the magnitude of change in the location of the place of use of a given service was not the biggest for A1/DK91 (16.1\% of the respondents stated a change in the location of use of a shopping centre) and A4/DK94 (10.0\%), but for DK8 over the segment Kudowa-Zdrój-Wrocław $(24.2 \%)$ or DK17 (10.5\%), see Table 2. Relatively high rates of changes were noted for the cultural services (cinemas), but also in this context the highest values have not appeared for these corridors, where the motorways function. Regarding the leisure-related trips (either the short-time ones - for the weekends, or the longer term ones - holidays) the changes were small. In this case, as well, an essential domination of the fast traffic roads over the other types of roads was not observed.

Table 2. Changes in the location of use of selected services (percentage shares of responses)

\begin{tabular}{|l|c|c|c|c|}
\hline \multicolumn{1}{|c|}{ Road corridor } & Shopping centres & Cinemas & Weekend outings & Holiday trips \\
\hline A1/DK91 & 16.1 & 11.6 & 4.7 & 4.2 \\
\hline A4/DK94 & 10.0 & 4.7 & 4.7 & 4.7 \\
\hline S8 & 10.3 & 4.7 & 1.7 & 2.2 \\
\hline DK8 Augustów-Budzisko & 5.3 & 3.7 & 3.4 & 3.1 \\
\hline DK8 Kudowa-Zdrój-Wrocław & 24.2 & 16.7 & 5.0 & 6.7 \\
\hline DK17 & 10.5 & 4.2 & 2.4 & 2.2 \\
\hline
\end{tabular}

Source: own elaboration on the basis of the questionnaire survey.

For the majority of the services analysed the assessment of changes in the frequency of their use is similar for the car owners and the remaining respondents. This is not surprising, since the frequency of use of the obligatory services is independent of the possibility of travelling to the locations of their provision. On many occasions the assessment, given by the persons not owning a car, was higher than that of the car owners. The situation is different for the facultative trips, like those related to the entertainment and cultural services, weekend outings, or visits at the large shopping centres, usually located far from the place of residence (investigations were conducted primarily within the rural areas). The use of these services is much easier for the car owners.

\section{Quality of life and level of safety}

Realisation of road projects should also bring measurable effects in the form of improved social satisfaction with respect to quality of life and safety of traffic, including that of pedestrians.

The broad notion of the quality of life referred, in the case of the questionnaire design, to the direct influence of the road corridors on everyday functioning of people. This issue encompassed such elements as the nuisance from the noise, associated with the car traffic (both during the day and during the night), and, in this connection, the functioning of the sound-absorbing screens (in the 
cases of A1, A4, and S8), as well as the nuisance, related to the smell of exhausts. On the other hand, the notion of safety referred not only to the safety of the cars, but also of other users of the roads, pedestrians and bikers. The question of the possibility of movement and safety of the handicapped persons was also accounted for.

The negative assessment of the particular components of the quality of life was formulated by the respondents for the cases of the two-way traffic roads, especially of the national road no. 8 over the segment Augustów-Budzisko (Table 3). This assessment is linked with the high intensity of traffic, mainly of the heavy loads, and the poor state of the road surface (in the opinion of the respondents). According to the self-governmental authorities there exist possibilities of improving the safety in the local traffic through enhanced smoothness of traffic on the national road (left turn lanes, bicycle paths, etc.) and an adequate organisation of the traffic. Social reception is much more positive with respect to the fast traffic roads, and this opinion got confirmed through the information, obtained during the interviews with the representatives of the self-governmental authorities. It is interesting to note that the highest assessments concerned the expressway S8, which follows the old route of the national road, and hence does not omit the particular localities to the same extent as the motorways do. In this context it appears that the nuisance from the noise and exhausts was assessed, in the case of the motorways, as relatively limited.

Table 3. Assessments of the component elements of the quality of life

\begin{tabular}{|c|c|c|c|}
\hline \multirow[b]{2}{*}{ Road corridor } & Noise (day) & Noise (night) & Exhaust gases \\
\hline & \multicolumn{3}{|c|}{$\begin{array}{l}\text { (scores on the scale of } 1-6 \text {, where } 1 \text { denotes high, and } 6 \text { low degree } \\
\text { of nuisance) }\end{array}$} \\
\hline A1 & 3.8 & 3.9 & 3.8 \\
\hline DK91 & 3.5 & 3.7 & 3.4 \\
\hline A4 & 3.7 & 3.8 & 3.7 \\
\hline DK94 & 3.1 & 3.4 & 3.0 \\
\hline S8 & 4.1 & 4.2 & 3.9 \\
\hline DK8 Augustów-Budzisko & 1.8 & 1.8 & 1.7 \\
\hline DK8 Kudowa-Zdrój-Wrocław & 2.9 & 3.3 & 2.9 \\
\hline DK17 & 3.0 & 3.3 & 3.3 \\
\hline
\end{tabular}

Source: own elaboration on the basis of the questionnaire survey.

Similarly as in the case of the quality of life, the lowest assessment scores for the level of safety of car driving concerned the two-way traffic roads, especially the national road no. 8 over the segment Augustów-Budzisko (average score of 1.9 on the scale of 1 through 6). The level of safety was also assessed as low for the same national road over the segment Kudowa Zdrój-Wrocław (score of 2.7). It is understandable that the highest scores were assigned the fast traffic roads (A1: 4.9, S8: 4.5, A4: 4.3). The national road no. 8 was negatively assessed on both segments considered in the context of the safety of pedestrians and the persons with limited possibilities of movement (handicapped persons, mothers with children, etc.), the scores taking values from the range of 1.6 to 1.8. It appears that this is not only the issue of high traffic intensity and lack of shoulder lanes, but the general poor assessment of safety of the pedestrians irrespective of the road category. The respondents gave only slightly higher scores regarding the safety of movement on the local roads (scores ranging between 2.6 and 2.8). The safety of the local car traffic was assessed by the respondents yet a bit higher for 
the road corridors A1/DK91 (3.6), A4/DK94 (3.5), and S8 (4.2). This is associated with at least partial transfer of the transit traffic from the national roads over to the motorways and decrease of traffic on the national and local roads, as confirmed by the earlier works (see, e.g., Komornicki et al., 2013). On the other hand, though, after the toll fees had been introduced on the national roads for the heavy loads, there has been a shift over to the local roads, which significantly lowered the safety of the movements of pedestrians and bikers (scores at the level of 2.5-2.7). Such a conclusion results, as well, from the interviews, conducted in the municipal offices.

\section{Conclusions}

The assessment of accessibility of the basic public services for the inhabitants of the self-governmental units considered indicates that the neighbourhood of the modern road infrastructure does not influence the opinion on the accessibility to the basic services, located at the municipal level, and even at the county level. The difference gets visible for the services, located in bigger towns (including the provincial capitals). The inhabitants of the municipalities, neighbouring upon the analysed motorways and expressways, point out a better (in comparison with the persons, residing close to other analysed national roads) access to large shopping centres, provincial administration, and universities. Among the new roads considered a bigger influence on the access to services appears to be exerted by the roads A1 and S8, with A4 exerting a relatively weaker influence. This fact could be assigned to the bigger distance of A4 from the settlement network, which causes that its role in the access to the closest big city, Wrocław, is similar to that of the national road DK94. At the same time, the motorway A1 and the expressway S8 brought distinctly closer the rural areas, through which they pass, to the service infrastructure of, respectively, Gdansk and Warsaw.

It should be emphasised that the improvement in the accessibility of the higher order services concerns, first of all, the individual transport, and to a lesser extent the public transport. Opening of the new motorways on the segments analysed here did not contribute to the appearance of the new coach lines, which might have had an impact on the accessibility of services with public transport. On the other hand, the effect of decreased traffic on the national roads, due to the opening of the parallel motorways, was annulled by the introduction of toll fees for the heavy loads over some of the national roads, which resulted in a partial shift of the traffic onto the local roads.

There is no essential difference in the assessment of accessibility of the public services (in total) for the car owners and persons not owning a car. This may be the effect of both the objective factors of organisational and infrastructural nature (e.g. an extensive network of public transport connections) and the subjective factors, related to the entirely different expectations of the car owners and the remaining persons.

No essential changes have been observed with respect to the motivations of the obligatory travels (job commuting, first of all) in the consequence of opening of an alternative possibility of travelling in the form of paid motorway. The economic calculus decidedly dominates over the time costs, borne during job commuting over the analysed national roads. The share of persons using the motorways increases in the case of facultative trips, especially to the shopping centres. Such trips are made less frequently, and hence the toll payment does not constitute a significant obstacle.

On all the roads considered (both the new and the old ones) the increase of frequency of travels was most distinctly observed for the case of such destinations as large shopping centres or weekend leisure. To a somewhat lesser extent this was also visible for the holidaymaking, banks, facilities of 
culture (cinemas, theatres), and the health care infrastructure (hospitals, dispensaries, and pharmacies). The comparison of changes in the municipalities neighbouring upon the new projects and those situated next to the old roads implies that the former might have generated the new traffic towards such services as centres of culture, provincial administration, as well as the railway stations. In the remaining cases (here - the shopping centres) the increase took place irrespective of the existence of the new infrastructure. This, however, does not mean that the new infrastructure has not exerted influence upon the location of the concrete places of realisation of the definite types of services.

The old reference roads analysed got negative assessments with respect to the daily nuisance associated with noise and emission of exhaust gases, and with respect to the levels of traffic safety, including the safety of pedestrians, bikers, and persons with limited capacities of moving. Distinctly higher assessment scores, both regarding quality of life and the level of safety, were given the fast traffic roads.

Taking into account the potential modifications to the currently conducted transport policy, the improvement of accessibility of the public services (especially within the peripheral areas) should be understood as the action, ultimately oriented at the provision of better communication for the areas, situated close to the national boundaries, within the borderlands of the particular provinces (low accessibility to the regional centres), as well as the places, where accessibility is limited by the natural factors (orographic, hydrographic, or resulting from the shape of the coastline and from the location of the protected areas). It seems to be purposeful to increase the density of nodes along the existing and planned motorways. The basis for the respective decisions must necessarily be constituted by the evaluation of accessibility of the centres on the regional and local scale, and not only by the stiff technical standards (definite distance between the junctions, highly differentiated, anyway, for various countries of the European Union).

Minimisation of the negative effects, appearing on the local scale, may be performed in several complementary ways. The most important of them, it appears, is to take into account the potential problems at the stage of taking decisions on the course of routes over the old or new road tracks (with strong preference for the latter solution). Besides, it is essential to carry out the adequately broadly conceived and appropriately early social consultations, encompassing not only the inhabitants, but also, to the same extent, local entrepreneurs, as well as the persons, managing the entities active in the sphere of basic services.

\section{References}

Ackerman F., Heinzerling L., 2004. Priceless: On Knowing the Price of Everything and the Value of Nothing. New York: New Press.

Besley T., Ghatak M., 2001. Government versus Private Ownership of Public Goods. Quarterly Journal of Economics, 116(4), pp. 1343-1372.

Breuer I.M., Milbert A., Foss O., Humer A., Palma P., Rosik P., Stępniak M., Velasco X., 2013. European Atlas of Services of General Interest. Bonn: BBSR.

Daniels R., Trebilcock M., 1996. Private Provision of Public Infrastructure: An Organizational Analysis of the Next Privatization Frontier. University of Toronto Law Journal, 46, pp. 375-426.

de Bettignies J.-E., Ross, T.W., 2004. The Economics of Public-Private Partnerships. Canadian Public Policy / Analyse de Politiques, 30(2), pp. 135-154. 
Domańska A., 2006. Wplyw infrastruktury transportu drogowego na rozwój regionalny. Warszawa: PWN.

Guzik R., 2003. Przestrzenna dostęność szkolnictwa ponadpodstawowego. Kraków: Wydawnictwo Instytutu Geografii i Gospodarki Przestrzennej Uniwersytetu Jagiellońskiego.

King S., Pitchford R., 2000. Private or Public? A Taxonomy of Optimal Ownership and Management Regimes. Working Paper, Melbourne: University of Melbourne.

Komornicki T. (ed.), 2013. Services of General Interest in European Union. EUROPA XXI, Volume 23, Warsaw: IGSO PAS.

Komornicki T., Rosik P., Śleszyński P., Solon J., Wiśniewski R., Stępniak M., Czapiewski K., Goliszek S., 2013. Wplyw budowy autostrad i dróg ekspresowych na rozwój społeczno-gospodarczy i terytorialny Polski. Warszawa: Ministerstwo Rozwoju Regionalnego.

Moene K.O., Wallerstein M., 2003. Earnings Inequality and Welfare Spending: A Disaggregated Analysis. World Politics, 55(4), pp. 485-516.

OECD, 2002. Distributed Public Governance. Agencies, Authorities and Other Government Bodies. Paris: OECD.

Rattsø J., 2002. Fiscal controls in Europe. A summary. [in:] B. Dafflon (ed.), Local Public Finance: Balanced Budget and Debt Control in European Countries, Cheltenham: Edward Elgar.

Stępniak M., Spiekermann K. (eds.), 2013. Transport accessibility at regional scale in Europe. EUROPA XXI, Volume 24, Warsaw: IGSO PAS.

Svallfors S., Taylor-Gooby P. (eds.), 2005. The End of Welfare State? Responses to State Retrenchment. London-New York: Routledge.

Taylor Z., 1999. Przestrzenna dostępność miejsc zatrudnienia, ksztatcenia i ustug a codzienna ruchliwość ludności wiejskiej. Prace Geograficzne no. 171, Wrocław: IGiPZ PAN, Wydawnictwo Continuo.

Vogel J. (ed.), 2003. European Welfare Production. Institutional Configuration and Distributional Outcome. Social Indicators Research Series, Volume 18, New York: Springer Science+Business Media. 